\title{
Crescimento de noni (Morinda citrifolia L.) em sistema consorciado com bananeira (Musa ssp), sob efeitos de adubação não convencional
}

\author{
Gessica Caitano de Almeida ${ }^{1}$; Thiago do Nascimento Coaracy ${ }^{2}$; Cid Eduardo Barreto Menezes ${ }^{3}$; Thiago Vital dos \\ Santos $^{4}$; Thallis de Souza Teixeira ${ }^{5}$; Belísia Lúcia Moreira Toscano Diniz ${ }^{6}$
}
Universidade Federal da Paraíba; ${ }^{1}$ gcaitano29@gmail.com; ${ }^{2}$ thiago.vt25@ hotmail.com; ${ }^{3}$ cideduardo1@ @otmail.com; thiago.coaracy@gmail.com; ${ }^{5}$ thallis.teixeirathalis@outlook.com; ${ }^{6}$ belisia.diniz@gmail.com.

\begin{abstract}
RESUMO: Informações sobre as exigências do noni (Morinda citrifolia Linn) em adubação são limitadas, principalmente no Brasil, e considerando a expansão da cultura, estudos sobre adubação e estratégias para aprimorar as técnicas de rendimento e reduzir os custos de produção devem ser adotados. De tal modo objetivando alcançar meios de produção mais sustentáveis, com esta pesquisa busca-se atender as necessidades da cultura por meio de uso de adubação não convencional, avaliando o crescimento e desenvolvimento da planta do noni sob tratamentos com diversas doses de biofertilizante de dejetos bovino, adubação verde com feijão de porco (Canavalia ensiformis), e consorciado com bananeira. A pesquisa ocorreu numa área experimental em campo, pertencente ao Setor de Agricultura do Centro de Ciências Humanas, Sociais e Agrárias, Campus III, da Universidade Federal da Paraíba, localizada no município de Bananeiras, PB. O delineamento utilizado foi em blocos casualizados adotando o esquema fatorial com tratamentos adicionais. As variáveis obtidas na pesquisa foi altura e diâmetro da planta, com os resultados obtidos conclui-se que, dentre os tratamentos aplicados, houve influência significativa apenas para a variável altura da planta, sob a interação do consórcio e adubação verde com feijão de porco.
\end{abstract}

PALAVRAS-CHAVE: Sustentáveis; Significativa; Interação.

\section{INTRODUÇÃO}

Ao cultivar determinada planta esperar-se a obtenção de resultados satisfatórios como retorno ao trabalho e investimentos da ação, mas para alcançar efeitos significativos requer conhecimentos referente a cultura implantada como, exigências edafoclimáticas, nutricional e manejos adequados. De acordo com Sousa et al. (2010), o desconhecimento da fertilidade do solo cultivado e, principalmente, da exigência nutricional da planta leva a práticas de manejo inadequadas que podem comprometer o crescimento, a produção e qualidade dos seus frutos. Para o cultivo do noni (Morinda citrifolia Linn) não seria diferente, pois embora ainda não seja uma cultura de expressão comercial poderá ser, num futuro bem próximo, tendo como base ao avanço das pesquisas, comprovando a importância das propriedades funcionais desta planta. Assim faz-se necessário avançar também os conhecimentos referente a fisiologia e fenologia do noni, para estar apto ao cultivo com finalidade comercial.

Informações sobre as exigências do noni em adubação são limitadas, principalmente no Brasil, e considerando a expansão da cultura, estudos sobre adubação e estratégias para aprimorar as técnicas de rendimento e reduzir os custos de produção devem ser adotados. De tal modo objetivando alcançar meios de produção mais sustentáveis busca-se atender as necessidades da cultura por meio de uso de adubação não convencional, a qual está sendo cada vez mais difundida, por favorecer fatores tanto econômicos quanto ambientais.

Moreira et al. (2013) afirma que, em pesquisas realizadas anteriormente com Morinda citrifolia L. o adubo orgânico mostrou-se com a mesma eficiência do adubo sintético, evidenciando, assim, o potencial da utilização de adubo natural. Portanto, o emprego do composto orgânico como fertilizante é um manejo viável nutricionalmente e economicamente para a cultura do noni. Deste modo, crescimento e desenvolvimento da planta do noni consorciado com bananeira, sob efeito de adubação não convencional é o tema principal deste trabalho, objetivando avaliar o crescimento e desenvolvimento da planta do noni sob efeitos de adubação com biofertilizante bovino e adubação verde com feijão de porco (Canavalia ensiformis), com e sem consórcio com bananeira.

\section{MATERIAL E MÉTODOS}

A pesquisa ocorreu numa área experimental em campo, pertencente ao Setor de Agricultura do Centro de Ciências Humanas, Sociais e Agrárias, Campus III, da Universidade Federal da Paraíba, localizada no município de Bananeiras, PB. O clima da região é classificado como As' que significa quente e úmido (BRASIL, 1972).

$\mathrm{O}$ delineamento utilizado foi em blocos casualizados adotando o esquema fatorial com tratamentos adicionais, $2 \times 2 \times 4+4$, referente a três repetições com duas plantas de noni por parcela com e sem consórcio com bananeira, os quais obtiveram tratamentos com e sem adubação verde com feijão de porco e quatro níveis de adubação com biofertilizante de dejeto bovino fresco $(0 ; 2,5 ; 5 ; 7,5$ litros de biofertilizante diluído em água até atingir 15 litros de solução por planta), mais quatro tratamentos adicionais com três repetições cada, visando avaliar o efeito dos tratamentos aplicados nas diferentes plantas (noni e bananeira), de forma individualizada. 
ALMEIDA, G. C. et al. Crescimento de noni (Morinda citrifolia L.) em sistema consorciado com bananeira (Musa ssp), sob efeitos de adubação não convencional. In: II Congresso Paraibano de Agroecologia \& IV Exposição Tecnológica, 2019. Anais Caderno Verde de Agroecologia e Desenvolvimento Sustentável, Pombal, v. 9, n.7, e-7029, 2019.

Foi produzido cerca de 600 litros de biofertilizante armazenados em bombonas de 200 litros, sendo necessário o uso de $120 \mathrm{Kg}$ de esterco bovino fresco, usado como base para o preparo, seis litros de leite com intuito de aumentar a quantidade de microrganismos, seis quilos de açúcar mascavo que se apresentam como fonte de energia imediata para as colônias de bactérias, três quilos de pó de rocha que serve como um condicionador, 150 gramas de fermento biológico para acelerar o processo de fermentação, e por fim 469 litros de água, todas a solução foi homogeneizada e hermeticamente fechada de forma a evitar a entrada de ar propiciando apenas a saída de gases por meio de uma mangueira imersa em uma garrafa pet contendo água, e armazenado por um período de 30 dias.

No decorrer deste tempo foi realizado a limpeza da área e das plantas, como poda de limpeza, coroamento das plantas, plantio das bananeiras, destaque dos frutos presente nas plantas e finalizando este tempo com o plantio do feijão de porco nos tratamentos devido. No mesmo período do plantio do feijão ocorreu a abertura e aplicação do biofertilizante, seguindo da primeira coleta de dados (altura e diâmetro das plantas).

Após a aplicação do biofertilizante, foi aguardado um período de 2 meses, para realizar nova preparação de um novo lote de adubo. Assim a aplicação do bio ocorreu de forma trimestral e a coleta de dados mensal, assim como a capina da área visando o controle de plantas espontâneas.

Ao finalizar o período de maturação do bio foi realizado a análise química do produto, objetivando identificar os elementos adicionado a cultura, conforme representados na tabela 1 e 2 .

Tabela 1. Caracterização química do biofertilizante de dejeto bovino.

\begin{tabular}{llllllll}
\hline $\mathbf{U}$ & $\mathbf{C T}$ & $\mathbf{C O}$ & $\mathbf{C u}$ & $\mathbf{Z n}$ & $\mathbf{F e}$ & $\mathbf{M n}$ & $\mathbf{B}$ \\
\hline & $\%$ & & --10 & & \\
\hline 96,98 & - & - & 0,18 & 0,95 & 44,88 & 11,28 & 0,65 \\
\hline
\end{tabular}

Tabela 2. Caracterização química da solução de biofertilizante de dejeto bovino.

\begin{tabular}{|c|c|c|c|c|c|c|c|c|c|c|c|c|c|}
\hline pH & C.E. & $\mathrm{SO}_{4}^{-2}$ & $\mathbf{M g}^{++}$ & $\mathbf{N a}^{+}$ & $\mathbf{K}^{+}$ & $\mathbf{C a}^{++}$ & $\mathrm{CO}_{2}^{-}$ & $\mathrm{HCO}_{3}^{-}$ & $\mathrm{Cl}^{-}$ & $\mathbf{P}$ & $\underset{+}{\mathrm{NH}_{4}}$ & $\mathrm{NO}_{3}$ & $\mathrm{NO}_{2}^{-}$ \\
\hline $\begin{array}{c}\mathrm{dS} \mathrm{m}^{-} \\
\mathrm{a} \\
25^{\circ} \mathrm{C}\end{array}$ & & & & -.--- & $-\mathrm{mmol}$ & $L^{-1} \quad--$ & -1- & & & ---- & - & $\mathrm{mgL}^{-1}$ & ---- \\
\hline 5,1 & 5,59 & 7,89 & 64,00 & 6,00 & 15,71 & 27,50 & 0,0 & 160,00 & 30,0 & 210,70 & 0,82 & 0,30 & $<0,035$ \\
\hline
\end{tabular}

O feijão de porco foi plantado no quadrante de acordo com a projeção da copa das plantas, de forma a propiciar efeitos as plantas tratadas.

Para melhor representação dos tratamentos em campo, foram utilizadas as letras C, F, B e A, onde C1 representa os tratamentos sem o consórcio com bananeira e C2 com o consórcio; F1 tratamentos sem a adubação verde com feijão de porco e F2 com a adubação verde; B1, B2, B3, B4 é referente às respectivas doses de biofertilizantes aplicados; A1 refere ao noni sem o feijão de porco e A2 o noni com o feijão de porco; A3 é referente a bananeira sem o feijão de porco e A4 bananeira com o feijão de porco. Conforme descrito no quadro 1. 
ALMEIDA, G. C. et al. Crescimento de noni (Morinda citrifolia L.) em sistema consorciado com bananeira (Musa ssp), sob efeitos de adubação não convencional. In: II Congresso Paraibano de Agroecologia \& IV Exposição Tecnológica, 2019. Anais Caderno Verde de Agroecologia e Desenvolvimento Sustentável, Pombal, v. 9, n.7, e-7029, 2019.

Quadro 1. Descrição dos Tratamentos.

\begin{tabular}{|c|c|c|c|c|c|c|c|c|c|}
\hline T1 & T2 & T3 & T4 & T5 & T6 & T7 & T8 & T9 & T10 \\
\hline $\mathrm{C}_{1} \mathrm{~F}_{1} \mathrm{~B}_{1}$ & $\mathrm{C}_{1} \mathrm{~F}_{1} \mathrm{~B}_{2}$ & $\mathrm{C}_{1} \mathrm{~F}_{1} \mathrm{~B}_{3}$ & $\mathrm{C}_{1} \mathrm{~F}_{1} \mathrm{~B}_{4}$ & $\mathrm{C}_{1} \mathrm{~F}_{2} \mathrm{~B}_{1}$ & $\mathrm{C}_{1} \mathrm{~F}_{2} \mathrm{~B}_{2}$ & $\mathrm{C}_{1} \mathrm{~F}_{2} \mathrm{~B}_{3}$ & $\mathrm{C}_{1} \mathrm{~F}_{2} \mathrm{~B}_{4}$ & $\mathrm{C}_{2} \mathrm{~F}_{2} \mathrm{~B}_{1}$ & $\mathrm{C}_{2} \mathrm{~F}_{2} \mathrm{~B}_{2}$ \\
\hline $\mathbf{T 1 1}$ & $\mathbf{T 1 2}$ & $\mathbf{T 1 3}$ & $\mathbf{T 1 4}$ & $\mathbf{T 1 5}$ & $\mathbf{T 1 6}$ & $\mathbf{T 1 7}$ & $\mathbf{T 1 8}$ & $\mathbf{T 1 9}$ & $\mathbf{T 2 0}$ \\
\hline $\mathrm{C}_{2} \mathrm{~F}_{2} \mathrm{~B}_{3}$ & $\mathrm{C}_{2} \mathrm{~F}_{2} \mathrm{~B}_{4}$ & $\mathrm{C}_{2} \mathrm{~F}_{1} \mathrm{~B}_{1}$ & $\mathrm{C}_{2} \mathrm{~F}_{1} \mathrm{~B}_{2}$ & $\mathrm{C}_{2} \mathrm{~F}_{1} \mathrm{~B}_{3}$ & $\mathrm{C}_{2} \mathrm{~F}_{1} \mathrm{~B}_{4}$ & $\mathrm{~A}_{1}$ & $\mathrm{~A}_{2}$ & $\mathrm{~A}_{3}$ & $\mathrm{~A}_{4}$ \\
\hline
\end{tabular}

A avaliação do crescimento foi feita por meio de medição em altura do intervalo entre o colo até a inserção do último par de folhas da planta, utilizando uma fita milimétrica. O diâmetro caulinar foi medido a $10 \mathrm{~cm}$ do colo da planta com a suta, obtendo três medidas por planta em ângulos diferente, da qual foi feita a média para a planta. A análise estatística dos dados foram realizados utilizando o programa estatístico R. As plantas de noni avaliadas nesta pesquisa tem 8 anos de implantadas nesta área, onde vem passando por diversos processos de manejos todos de bases agroecológicas.

\section{RESULTADOS E DISCUSSÃO}

Os resultados expressos na tabela 3, foram conseguidos dos tratamentos realizados, estando representado o resumo da análise de variância, obtidas das variáveis altura e diâmetro da planta do noni, referente aos tratamentos aplicados.

Tabela 3: Resumo da análise de variância.

\begin{tabular}{|c|c|c|c|c|c|}
\hline \multirow[t]{2}{*}{ Fatores de Variação } & \multirow[t]{3}{*}{ GL } & DPN (cm) & \multicolumn{3}{|c|}{ APN (m) } \\
\hline & & QM & $\mathrm{F}$ & QM & $\mathrm{F}$ \\
\hline & & & NS & & NS \\
\hline \multirow[t]{2}{*}{ Biofertilizantes } & 3 & 0,65563 & & 0,01745 & \\
\hline & & & NS & & NS \\
\hline \multirow[t]{2}{*}{ Feijão } & 1 & 2,79384 & & 0,15972 & \\
\hline & & & NS & & NS \\
\hline \multirow[t]{2}{*}{ Consórcio } & 1 & 6,27741 & & 0,03869 & \\
\hline & & & NS & & NS \\
\hline \multirow[t]{2}{*}{ Biofertilizantes*Feijão } & 3 & 0,7961 & & 0,02847 & \\
\hline & & & NS & & NS \\
\hline \multirow[t]{2}{*}{ Biofertilizantes*Consórcio } & 3 & 2,14768 & & 0,0045 & \\
\hline & & & NS & & $*$ \\
\hline \multirow[t]{2}{*}{ Feijão*Consórcio } & 1 & 1,94821 & & 0,34643 & \\
\hline & & & $\mathrm{NS}$ & & NS \\
\hline Biofertilizantes*Feijão*Consórcio & 3 & 2,48636 & & 0,03173 & \\
\hline \multicolumn{2}{|l|}{ Valor-p } & \multicolumn{2}{|c|}{0,2102381} & \multicolumn{2}{|c|}{0,9068276} \\
\hline
\end{tabular}


ALMEIDA, G. C. et al. Crescimento de noni (Morinda citrifolia L.) em sistema consorciado com bananeira (Musa ssp), sob efeitos de adubação não convencional. In: II Congresso Paraibano de Agroecologia \& IV Exposição Tecnológica, 2019. Anais Caderno Verde de Agroecologia e Desenvolvimento Sustentável, Pombal, v. 9, n.7, e-7029, 2019.

Pela análise geral das variáveis demonstrado na tabela 3, podemos verificar que até o presente momento do experimento, os tratamentos aplicados não influenciaram o diâmetro da planta do noni e não houve interação significativa. Já observando a variável altura da planta do noni, nota-se que houve apenas influência significativa na interação feijão e consórcio.

Tabela 4: Resultados dos valores da variável altura da planta do noni.

\begin{tabular}{lll}
\hline Tratamentos & Sem feijão & Com feijão \\
& & \\
\hline & & $2,2518^{\mathrm{bb}}$ \\
Sem consórcio & $2,2811^{\mathrm{ba}}$ &
\end{tabular}

$$
2,3433^{\mathrm{ab}}
$$

\author{
Com consórcio $\quad 2,0825^{\mathrm{bb}}$ \\ *Médias seguidas de letras minúsculas iguais não diferem $(\mathrm{P}>0,05)$ estatisticamente pelo teste de Tukey.
}

Ao fazer uma análise da tabela 4 nota-se que, as médias dos tratamentos sem consórcio e com e sem feijão não diferem estatisticamente, enquanto que, ao consorciar percebe-se a diferença entre as médias dos tratamentos com e sem feijão, e ao fazer o desdobramento estatístico foi constatado que na interação dos tratamentos observados na tabela, o cultivo consorciado é quem propicia melhor resposta a curto prazo ao crescimento vegetativo da planta, tendo em vista que os dados analisados são dos três meses de consórcio destas plantas.

O manejo alternativo nos sistemas de produção visa alcançar melhor eficiência produtivas, aliado à sustentabilidade ambiental e proporcionando a maior segurança alimentar. Assim entenda os termos consórcio, adubação verde e adubação com biofertilizante.

Produção em sistemas de consórcio é uma prática de cultivo bem recomendadas, e na maioria dos casos uma prática muito sustentável tendo em vista propiciar benéfico mútuo a planta, solo e aos organismos deste. O consórcio do noni com bananeira, é uma prática que benéfica a ambas as culturas, pois o compartilhamento e trocas de nutrientes é o fator chave deste sistema de cultivo, tendo em vista a alta demanda de potássio do noni e a grande disponibilidade deste pela bananeira. Alencar e Azevedo 2018, complementa ainda que, esse tipo de cultivo pode ser considerado uma condição para o alcance da sustentabilidade na agricultura, tanto por motivos ambientais, quanto por motivos econômicos e sociais.

Em se tratando de adubação verde Moreira (2013), a define como, a arte de enriquecer (adubar) o solo com algumas plantas que lhe geram benefícios, como: Formar e aumentar a quantidade de matéria orgânica e microorganismos do solo; Deixar a terra mais úmida e mais fresca; Melhorar a infiltração da água; Deixar a terra mais porosa para circular mais oxigênio; Descompactar (romper e afofar) camadas do solo, quando o mesmo se encontra impenetrável para as raízes das plantas; Adicionar o nitrogênio (alimento), que é fornecido pelas plantas da família das leguminosas; Melhorar a estrutura do solo e o deixar com a cor mais escura, em consequência do aumento da matéria orgânica.

O biofertilizante é a prática de produção de adubo por meio da ação de microrganismo seja aeróbico ou anaeróbico. O benefício deste tipo de adubação é que, fornece uma variedade de nutriente ao solo a maioria já disponível às plantas, e tende a propiciar condições a manutenção de organismos do solo, acarretando em efeito a longo prazo, tanto ao solo quanto a cultura.

\title{
CONCLUSÕES
}

Com os resultados obtidos conclui-se que, o consórcio de noni e bananeira é o tratamento mais viável a curto prazo para favorecer o crescimento vegetativo da planta. A pesquisa continua ativa para coleta de posteriores dados, assim sendo necessário a continuação de atividades para aprofundar os conhecimentos sobre nutrição de plantas com relação a essa cultura. 
ALMEIDA, G. C. et al. Crescimento de noni (Morinda citrifolia L.) em sistema consorciado com bananeira (Musa ssp), sob efeitos de adubação não convencional. In: II Congresso Paraibano de Agroecologia \& IV Exposição Tecnológica, 2019. Anais Caderno Verde de Agroecologia e Desenvolvimento Sustentável, Pombal, v. 9, n.7, e-7029, 2019.

\section{REFERÊNCIAS}

ALENCAR, I., \& AZEVÊDO, P. (2018). Caracterização do consórcio coqueiro-bananeira no Perímetro Irrigado das Várzeas de Sousa, PB. Agropecuária científica no semiárido, 14(1), 50-58.

BRASIL, Ministério da agricultura. (1972). Levantamento exploratório e conhecimento de solos do estado da Paraíba. Rio de Janeiro. MA/CONTAP/SAIDSUDENE, 670p. (Boletim técnico 15).

MOREIRA, V. R. R. Fertilidade do Solo e Nutrição de Plantas: Adubação verde. Coordenação de Agroecologia Ministério da Agricultura, Pecuária e Abastecimento: www.agricultura.gov.br/desenvolvimento-sustentavel/organicos organicos.mapa@agricultura.gov.br.

MOREIRA, Gustavo Gurgel et al. 14535-Acompanhamento de mudas de Morinda citrifolia cultivadas em campo submetidas a diferentes tipos de adubações. Cadernos de Agroecologia, v. 8, n. 2, 2013.

R Core Team (2019). R: A language and environment for statistical computing. R Foundation for Statistical Computing, Vienna, Austria. URL https://www.R-project.org/.

SOUSA, João A.; AQUINO, Antônio R. L.; FREIRE, Francisco das C. O.; SILVA NETO, Perpetuo A. Produção de Mudas de Noni (Morinda citrifolia L.). Comunicado técnico 157. Fortaleza - CE. EMBRAPA 2010.

\section{AGRADECIMENTOS}

Apoio financeiro: Fundação de Apoio à Pesquisa do Estado da Paraíba - FAPESQ. 